\title{
Newton e a Química Vegetal
}

\section{A. M. Amorim da Costa}

A visão de Newton sobre matéria química não se esgota na sua visão mecânica do Universo compaginada nos Principia Mathematica (1687). Partidário das filosofias corpusculares, ele acreditava que todos os corpos eram constituídos de partículas primitivas extremamente pequenas, sólidas, compactas, duras, impenetráveis e móveis, com tamanhos, figuras e proporções os mais adequados à formação dos compostos que constituem. Na secção final do seu tratado de Óptica (1704), encontramos toda uma série de questões relativas a especulações sobre a estrutura da matéria que complementadas por muitos dos seus escritos alquímicos, a que os estudiosos da sua obra só começaram a dar a devida atenção a partir dos anos trinta do século XX, levam-nos a uma outra visão, particularmente no que se refere aos fenómenos de natureza vegetal, nos quais se incluem os chamados fenómenos da "vegetação metálica". Deste modo, a Química Vegetal da Química dos nossos dias tem um significado muito diferente da Química Vegetal da obra de Newton.

\section{INTRODUÇÃO}

A partir da segunda metade do século XVI, sob a influência de Paracelso (1493-1541) e J. B. Van-Helmont (1579-1644), a prática da Química foi totalmente enquadrada na arte médica, constituindo o que ficou conhecido por medicina espagírica, iatroquímica ou farmacoquímica. Desenvolvida e aprofundada ao longo de todo o século XVII, esta orientação perdurou até ao terceiro quartel do século XVIII, ao tempo em que Lavoisier (1743-1794) lançou as bases da chamada "química pneumática". Em todo este período, a química e a farmácia foram duas práticas indissociáveis [1].

Nela pontificaram, em especial, os químicos do Jardin du Roi criado, em 1640, pelo Rei Luís XIII, nas margens do Sena, em Paris, com destaque para Jean Béguin (1550-1620), Nicaise Le Febvre (1610-1669), Christopher Glaser (1615-1672) de quem foi discípulo Nicolas Lémery (1645-1715), mais tarde, professor de química na Escola de Farmácia de Montpellier e autor do mais influente Manual de Química do século XVII, com mais de treze edições enquanto era ainda vivo [2] e G. François Rouelle (1703-1770) de quem foram alunos, entre outros, D. Diderot (1713-1784), Joseph Proust (1754-1826) e A. Lavoisier. Todos eles químicos e farmacêuticos por profissão, pouco devotados a grandes especulações teóricas, unanimemente

Dept. Química, Universidade de Coimbra, 3004-535

acosta@ci.uc.pt consideraram que o grande objectivo e empenho da tarefa química deveria ser a preparação dos medicamentos necessários à receita médica.

J. Béguin deixou-o bem claro, em 1604, numa série de lições públicas sobre matéria química e, anos depois, em 1610, no tratado Tyrocinium Chymicum, destinado aos principiantes em química. Nele define a química como "a procura prática e experimental dos medicamentos" [3,4]. O mesmo fizeram N. Le Febvre e C. Glaser nos tratados químicos que escreveram $[5,6]$.

Para prepararem os desejados medicamentos, os iatroquímicos recorriam a substâncias dos três reinos da Natureza, minerais, vegetais e animais, como amplamente o demonstram as muitas Farmacopeias que a partir de então foram sendo elaboradas e publicamente divulgadas. Todavia, conhecidas as dificuldades da solubilização da maioria dos metais e sua consequente dificuldade em serem assimilados pelos organismos que os ingerem, e, conhecidos também os muitos efeitos perniciosos, nomeadamente tóxicos, resultantes da ingestão de alguns deles, em doses inadequadas, sendo muito difícil encontrar o doseamento correcto, as substâncias do reino mineral sempre foram parte menor do elenco do receituário medicinal dos iatroquímicos, não obstante não aceitarem a posição do receituário galénico que os bania por completo.

Duarte Madeira Arraes (?-1652), médico do Rei D. João IV de Portugal, deixou-o bem claro ao recomen- dar que o médico metódico e douto se deveria abster tanto quanto possível de usar os medicamentos metálicos pois que, embora sejam "especiosos catárticos e façam efeitos admiráveis em gravíssimas e extremas doenças", "por mais que lhe pareçam que têm a decente preparaçam", "he impossivel que ainda assim não escape alguma qualidade venenosa e perniciosa de que os mineraes são bem aquinhoados"; (...) "até agora poucos foram os que particularmente usaram delles que chegassem a morrer velhos. E se lá chegaram, viveram cachéticos e hydropicos" [7].

De facto, a grande fonte das substâncias utilizadas pelos iatroquímicos sempre foi o Reino vegetal, na peugada das dezenas e dezenas de produtos da matéria médica elencados desde Dioscórides a Ibn Al Baiter a que se vieram juntar os muitos produtos vegetais com efeitos terapêuticos trazidos dos "novos mundos" das Descobertas seiscentistas.

Conhecê-los bem do ponto de vista químico tornou-se para eles uma tarefa obrigatória. Não foi por acaso que os iatroquímicos do Jardin du Roi montaram o seu laboratório de preparações farmacêuticas num Jardim, conhecido também por Jardim real das plantas medicinais que só em 1718 passaria a Jardim Real das Plantas e, depois da Revolução Francesa, a Jardim das Plantas, onde viria a ser formado o Museu Nacional de História Natural dos nossos dias. A prática da Química no Jardin du Roi, centrada no estudo de produtos farmacêuticos ex- 
traídos de compostos naturais, sobretudo os de origem vegetal, perdurou até ao século XIX. Nele trabalharam, entre outros, Fourcroy (1755-1809), N. L. Vauquelin (1763-1829), M. E. Chevreul (1786-1889) e Gay-Lussac (1778-1850), sendo de destacar o trabalho de Vauquelin na descoberta e isolamento de diversos alcalóides e toda uma série de compostos orgânicos extraídos de plantas. Herdeiro do Jardin du Roi, o Museu de História Natural de Paris tem, ainda hoje, nas suas instalações, um Laboratório de Química cujo objectivo primeiro é o estudo de substâncias naturais.

Não foi também por mero acaso que a criação de um grande número de jardins botânicos afectos a grandes instituições científicas teve a marca do interesse da iatroquímica. Basta que lembremos aqui o que sobre alguns deles referiu o Marquês de Pombal na carta que dirigiu a D. Francisco de Lemos, Reitor da Universidade de Coimbra, reprovando a planta apresentada por D. Vandelli (1730-1816) e Giovanni A. dalla Bella (1726-ca.1823) para o Horto Botânico que os Novos Estatutos dados à Universidade em 1772 determinavam se construísse. Opunha-se o Marquês à grandiosidade do jardim delineado pelos dois professores porque entendia que não servia ao fim desejado, aquele que vira praticado nos Jardins Botânicos das Universidades da Inglaterra, Holanda e Alemanha e Ihe constava que sucedia também no de Pádua, donde eram originários os dois professores: "todos estes jardins são reduzidos a um pequeno recinto cercado de muros, com as commodidades indispensáveis para um certo numero de hervas medicinais e próprias para o uso da faculdade medica; sem que se excedesse d'ellas a compreender outras hervas, arbustos e ainda árvores das diversas partes do mundo, em que se tem derramado a curiosidade dos sequazes de Linneu..." [8].

Este grande interesse químico pelas substâncias de origem vegetal constituiu aquilo que muitos dos químicos dos séculos XVII e XVIII trataram sob a designação de "Química Vegetal". Essencialmente centrada em problemas de análise química, procurando prioritariamente os princípios activos do ponto de vista farmacêutico de muitos dos componentes que era possível extrair das plantas, a Química Vegetal interessava-se também por todo o tipo de fenómenos relacionados com a sua fisiologia, com muitas experiências sobre a sua respiração e sobre os melhores processos de as conservar, como aconteceu, em particular, no Laboratório Chimico da Universidade de Coimbra nos anos que se seguiram à Reforma de 1772 [9].

A mesma designação é usada ainda hoje em muitos Manuais e Cursos de matéria química cujo objecto se centre no estudo químico de vegetais, um pouco à revelia da divisão da química, apresentada em 1777 por Torben O. Bergmann (1735-1784), em Química Orgânica e Química Inorgânica, relegando para esta última o estudo dos compostos de origem mineral, e incluindo na primeira o estudo de todos os compostos obtidos directamente dos seres vivos, animais ou vegetais.

A "Química Vegetal" era um dos assuntos do conteúdo da Química Orgânica. Outra não deverá ser, porventura, a sua caracterização e classificação se nos confinarmos estritamente ao estudo material dos compostos vegetais. A designação assume, todavia, um carácter polémico quando se ousa avançar para além do estritamente material. Desde logo é posto em causa o seu carácter científico. Não deixa de ser paradoxal que se deva a Isaac Newton (1642-1727), o pai mais consagrado da ciência moderna, a marca principal dessa polémica. É a ela que aqui nos queremos referir.

\section{Newton e a Química dos Vegetais}

A visão mecânica do Universo compaginada nos Principia Mathematica de Newton não é aquela que melhor traduz a visão do seu autor sobre matéria química [10]. Para bem nos inteirarmos sobre a sua posição a respeito desta é necessário analisar a secção final do seu tratado de Óptica [11] de 1704, onde encontramos toda uma série de questões relativas a especulações sobre a estrutura da matéria, numa abordagem essencialmente experimental; e é necessário, sobretudo, analisar muitos dos seus escritos relacionados com a sua intensa actividade como alquimista. Depois da descoberta, na década de 1930, de um grande volume de manuscritos de Newton sobre assuntos de alquimia que haviam passado despercebidos depois da sua morte, a faceta alquimista de Newton não pode deixar de ser tida na devida consideração quando se pretende estudar a sua posição em matérias do domínio da química. Deles se depreende que Newton dedicou um tempo imenso à alquimia, provavelmente maior do que à mecânica. Porque o fez no quadro de uma actividade privada e sem divulgação imediata, nem mesmo o seu assistente directo terá tido conhecimento pormenorizado dela. Hoje, referindo-nos à sua visão sobre matéria química, não a podemos ignorar.

Do ponto de vista da mecânica, Newton foi partidário das filosofias corpusculares acreditando que todos os corpos eram constituídos de partículas primitivas extremamente pequenas, sólidas, compactas, duras, impenetráveis e móveis, com tamanhos, figuras e proporções os mais adequados à formação dos corpos que constituem. Sólidas e incomparavelmente mais duras que quaisquer dos corpos porosos delas formados, tais partículas nunca se romperiam nem seriam desfeitas em bocados [12]. Combinando-se entre si e com porções de espaço vazio entre elas, essas partículas primitivas dariam origem a partículas maiores que, por novas combinações entre si e com outras porções de espaços vazios, acabariam por dar origem às diversas espécies de matéria visível e invisível. Tudo isto sob a acção de certas forças pelas quais, por causas que considerava ainda desconhecidas, seriam ou mutuamente impelidas umas para as outras, convergindo em figuras regulares, ou mutuamente repelidas. Tratar-se-ia de forças do tipo das forças da atracção universal que explicavam os fenómenos celestes, actuando a curta-distância, entre as partículas constituintes de todos os corpos [13,14].

Nesta sua visão mecânica da constituição da matéria, Newton confessava que por muitas razões era induzido a suspeitar que todos os fenómenos da natureza poderiam depender dessas 
forças pelas quais as partículas dos corpos, por algumas causas até então desconhecidas, seriam mutuamente impelidas umas em direcção às outras, formando corpos regulares, ou então mutuamente repelidas [15].

Lendo, todavia, os seus escritos relacionados com muitas das suas práticas de alquimia, por mais que uma vez o vemos afirmar a necessidade de outros princípios para além de tais forças, para explicar a complexidade do mundo físico. Em particular, quando se trata de explicar certos Princípios Activos que ele considerava serem responsáveis pelo complexo comportamento químico da matéria.

De facto, nestes escritos verificamos que Newton professava, neste domínio, a ideia de um universo preenchido pelo éter com elementos animistas, incluindo a crença numa substância subtil denominada magnésia, como princípio constitutivo dos materiais magnéticos, uma emanação que revivifica a matéria, e a crença numa "virtude fermental" ou espírito vegetal, a força da fermentação a que se referira em algumas das suas questões da Opticks. Esta seria uma autêntica entidade alquímica "o agente vital difundido através de todas as coisas que existem no Mundo; o espírito mercurial, mais subtil e completamente volátil, disperso através de todos os lugares ...".

Com a virtude fermental, Newton buscava um princípio único capaz de modificar a matéria e de produzir as suas múltiplas formas, inclusive as diversas formas de vida, para cuja geração seria necessário, em seu entender, algo mais que uma simples acção mecânica. Os filósofos naturais da época eram unânimes em afirmar que a simples acção mecânica jamais poderia dar conta de certo tipo de processos da natureza como, por exemplo, o processo de assimilação, no qual a comida se transforma nos corpos de animais, vegetais e minerais. Tão pouco poderia dar conta da grande variedade de formas no mundo, emanadas todas de uma matéria única. Pura e simplesmente, as leis mecânicas na base das quais seriam explicados, na sua generalidade, os fenómenos químicos não poderiam explicar todo o comportamento da matéria orgânica e inorgânica. Em particular, a química dos vegetais não poderia ser totalmente enquadrada no âmbito da matéria química. Um vegetal seria muito mais que um ser inanimado, possuindo uma respiração etérea para refrigerá-lo e para refrigerar também o seu fermento vital, num processo em que seriam emitidas fortes exalações.

Deste modo, a Química vegetal não poderia prescindir do estudo do espírito vital subtil que ele buscava, traduzido no mistério sagrado que envolvia a matéria na sua estrutura íntima. Para Newton, a Química vegetal extravasaria necessariamente o âmbito da química vegetal das preparações farmacêuticas da espagírica, nas suas manipulações de análise e síntese dos compostos vegetais. E não poderia ser confinada à visão mecânica da química que ele próprio caracterizara nos Principia e na Optiks.

Tentando caracterizar a virtude fermental dos vegetais, Newton foi um confesso adepto do animismo e da alquimia. Esta vertente da sua actividade permite-nos perceber quão arbitrárias e fluidas eram ainda as fronteiras entre magia e ciência ao tempo em que escreveu esses dois tratados básicos da ciência moderna. E ilustra de maneira clara as continuidades que, paralelamente às rupturas, moldaram a revolução de que nasceu a ciência moderna. Não é de todo defensável a existência de hiatos e descontinuidades radicais entre a ciência antiga, distorcida pela superstição e o empirismo ingénuo, e a ciência moderna, assente no empirismo racional. Pela dedicação com que cultivou uma e outra, e pela crença que em ambas depositou, Newton acabaria por ser considerado "o último dos magos e o primeiro dos físicos" [16].

\section{Metalogénesis e Palingénesis}

O animismo dos escritos alquimistas de Newton, que suporta o tratamento que fez da química vegetal na consideração duma virtude fermental traduzida numa emanação que revivifica a matéria vegetal como seu elemento constitutivo, estendeu-se aos seus estudos sobre os metais. Seduzido pelas ideias de Ireneu Filaleto sobre a exalação mineral no processo da formação dos metais, Newton deixou-se fascinar pela beleza da "teia" duma liga de cor púrpura viva que conseguiu preparar a partir de antimónio e cobre.

Hoje, qualquer de nós pode deixar-se possuir por igual fascínio, em nossas próprias casas, com preparações semelhantes, seguindo receitas muito simples, amplamente divulgadas em catálogos que referem o crescimento de cristais. Os "kits" da Smithsonian e outros estão ao alcance de todos. Com um sentimento de magia, é fácil preparar autênticos jardins de cristais, com um colorido deslumbrante, a partir de soluções muito simples de variados elementos metálicos. Seduzido por este fenómeno, Newton acreditava que a geração dos metais se processaria no seio da Terra-mãe, por transformações contínuas em tudo idênticas às transformações observadas nos vegetais. A química mineral e a química vegetal deveriam ter enquadramento similar, ambas empenhadas na caracterização de princípios e processos semelhantes. A formação ou génese dos metais no seio da Terra-mãe, a metalogénesis, seria, nos seus aspectos fundamentais, um processo de vegetação, a vegetação metálica. Conhecer a natureza da virtude fermental que está na sua origem, e o mecanismo da sua actuação, seria entrar no segredo e na posse da chave do processo da metalogénesis.

Ao tempo em que Newton se interessava pela virtude fermental da vegetação metálica, muitos dos estudiosos das plantas interessados na sua descrição e classificação interessavam-se também pela sua análise química, já no quadro das preparações farmacêuticas a que se dedicavam, já no quadro de estudos gerais de botânica. Era o que acontecia, em França, no já referido Jardin du Roi e também na Academia Real das Ciências e um pouco pelo resto da Europa, na Inglaterra, em Itália, na Polónia, etc. Nesta prática, a maceração dos mais variados tipos de plantas em frascos de vidro, aquecidos por utilização de diferentes graus de calor, começando com um banho de água mais ou 
menos quente, seguido de um aquecimento directo em fogo brando que se ia tornando cada vez mais intenso, tornou-se um processo rotineiro. Foi nesta prática que se desenvolveu um grande interesse pela chamada palingénesis, o processo da "ressurreição" duma planta destruída pelo fogo, a partir das cinzas formadas, a que nos referiremos mais adiante. Tal como na vegetação metálica, o que estaria em causa seria a natureza e o modo de acção da virtude fermental que actuaria num caso e noutro. Nela residiria a possibilidade do praticante de alquimia ser capaz de fazer, no curto tempo da vida de um vivente humano, o que a Natureza leva séculos no seio da Terra-mãe, a transformação dos metais vis em metais nobres, e também a possibilidade do elixir da longa vida, que num processo de "ressurreição" contínua aproximaria o homem mortal da imortalidade do próprio Deus.

Nesta convicção, Newton e os seus contemporâneos que partilhavam a mesma crença limitavam-se a fazer sua uma crença que vinha da Antiguidade Clássica e atravessara toda a Idade Média: a ideia generalizada entre os mineralogistas ocidentais de que os metais cresciam no seio das minas donde eram extraídos [17].

Pouco menos de um século antes de Newton, Jerónimo Cardan (15011576) referia-se ao assunto em termos bem claros: "o que é uma mina senão uma planta coberta de terra? Os metais existem nas montanhas do mesmo modo que as árvores, com as suas raízes, os seus troncos, os seus ramos e as sua folhas próprias" [18]. Por sua vez, séculos antes, R. Bacon (1219-1292) escrevia que "alguns escritores antigos referem que se podia encontrar na ilha de Chipre uma espécie de ferro que cortado em pequenos bocados e enterrado em terreno lavrado frequentemente, aí vegetaria de modo tal que todos os bocados enterrados se tornariam muito maiores" [19].

Com esta ideia, de que os metais nascem e crescem no seio da terra, muitos proprietários de minas iam ao ponto de suspender de tempos a tempos a actividade da sua exploração, deixando-as repousar, por períodos mais ou menos longos, para que a mina recuperasse do seu processo de formação, tal qual é habitual fazer com os terrenos de cultura vegetal.

Na Antiga Grécia, Aristóteles (384-322 a.C.) na sua obra Meteorológica [20] descreveu a formação das substâncias minerais em termos de exalações subterrâneas devidas ao calor do sol que penetrava através da crosta terrestre e se ia acumulando no seio da terra. Actuando sobre a humidade subterrânea, este calor levaria à formação de exalações húmidas que se libertariam das substâncias ali existentes, deixando-as com um excesso de exalações secas, o que explicaria a existência de substâncias líquidas e substâncias sólidas, substâncias em que predominaria o elemento água e substâncias em que predominaria o elemento Terra. Os metais seriam substâncias compostas resultantes da combinação, em proporções diversas, das substâncias com exalações húmidas com as substâncias com exalações secas, por interacção das próprias exalações [21].

Ainda na Antiguidade, Plínio, o Velho (23-79), tido como o mais importante naturalista do seu tempo, na sua História Natural escreveu que as minas de chumbo, em Espanha, donde se extraia a galena, "renasciam" ao fim de certo tempo [22]. Indicações semeIhantes encontram-se na Geografia de Strabo de Capadócia (57 a.C.-21 d.C.) [23] e muitos outros autores ao longo de toda a Idade Média.

Jorge Agricola (1494-1555), na sua obra De Re Metallica, o mais autorizado tratado sobre extracção e tratamento de metais nos 250 anos que se seguiram à sua primeira publicação em Basileia, no ano de 1556, num diálogo entre Daniel, um profundo conhecedor de todas as tradições mineralógicas, e um jovem mineiro ainda aprendiz, iniciando-o nas técnicas de rejuvenescimento das minas e na arte de extracção, refere outro tanto.

Também Paracelso, no seu livro De Mineralibus e no tratado sobre a Economia dos Minerais e sua Genealogia, confessa a sua crença no processo da vegetação metálica dizendo que nela, à semelhança do que se passa com as plantas, os minerais envoltos pelo elemento $\mathrm{Ar}$, germinam no seio da terra a partir de sementes jacentes no elemento matricial Água, com um período de desenvolvimento mais ou menos longo, até se tornarem espécimes amadurecidos. Na complexa matriz que é o seio da terra formada de substâncias com exalações húmidas e substâncias com exalações secas, da interacção de umas com as outras, resultaria a formação duma "árvore" com frutos prontos para serem coIhidos pelo homem quando chegada a estação própria. Se o homem não colher esses frutos no tempo próprio, eles tornam-se pó como em pó se tornam os frutos vegetais não colhidos. Mas, qual Fénix, das cinzas a que são reduzidos podem renascer em processo de renovação contínua. Por isso não se esgotarão jamais no seio materno em que são gerados. Cabe ao homem ressuscitá-los das cinzas em que jazem.

É na comunhão desta ideia centrada numa virtude fermental de metais e vegetais que metalogénesis e palingénesis assumem igual enquadramento conceptual e a química vegetal enquadra a vegetação metálica.

A terminologia usada pode ser encontrada na filosofia dos antigos Estóicos que a usavam para se referirem à contínua re-criação do Universo sob acção do Demiurgo depois de ter sido por ele absorvido. Filo de Alexandria (20 a.C.-50 d.C.) usara-a ao falar de Noé e seus filhos para referir a renovação e renascimento da terra após o dilúvio a que tinham sobrevivido. E Plutarco (45-125) usara-a para se referir à chamada metempsicose, a perenidade da alma que sobrevive à morte do corpo em que habita, por transmigração, à hora da morte dele, para um novo corpo, num processo de eterna renovação e eterno renascimento.

Todavia, a interligação da vegetação metálica de Newton com a virtude fermental que ele tinha como elemento intrínseco de todo o processo vegetativo, permite-nos estabelecer uma relação muito mais estreita entre os dois processos, a metalogénesis e a palingénesis pela qual havia, ao tempo de Newton, um grande e generalizado in- 
teresse, sobretudo entre aqueles que mais se interessavam pela química vegetal.

Muito desse interesse, sobretudo ao longo do século XVII, foi alimentado por um relato de Joseph Du Chesne (1546-1609), médico e Embaixador de Henrique IV, conhecido por Quercetanus, referindo uma experiência de que fora testemunha, num laboratório de Cracóvia, em que várias plantas teriam sido "ressuscitadas", após terem sido calcinadas, a partir das cinzas obtidas. De facto, este relato foi ao tempo, e por muitos anos, testemunho de referência sobre o fenómeno. O próprio Diderot, no seu texto sobre palingénesis na Enciclopédie, o refere com grande destaque.

Diz J. Du Chesne que um médico Polaco (cujo nome não menciona), em Cracóvia, o levou ao seu Laboratório e aí lhe mostrou as cinzas de diversas plantas pertencentes a diferentes espécies que conservava em mais de trinta frascos hermeticamente fechados. Tomando um desses frascos, o médico aqueceu-o durante algum tempo sob fogo brando. Maravilhado e espantado, Du Chesne assistiu ao germinar, no frasco, de um rebento que rapidamente tomou a cor, o formato e o tamanho da espécie original de que as cinzas provinham, acabando no desabrochar duma flor. Quando o médico deixou de aquecer o frasco, à medida que o arrefecimento se dava, a "ressuscitada" planta que dentro dele se formara transformou-se de novo nas cinzas de que brotara. Ali mesmo, o médico afiançou a Du Chesne que obtivera idênticos resultados utilizando cinzas de rosas, de túlipas e de calêndulas, podendo repetir as experiências vezes sem conta [24].

K. Digby (1603-1665) numa palestra de 1660, que intitulou de Discurso sobre a Vegetação das Plantas, foi um dos muitos autores que no século XVII manteve vivo o interesse pelo fenómeno da palingénesis, creditado no relato de Du Chesne, referindo ele próprio o interesse que ao assunto votaram muitos dos autores da época, com especial menção de A. Kircher (1602-1680) e W. Davisson (16621728) [25-29].
Ao interesse pela "ressurreição" de plantas a partir das suas cinzas se associou rapidamente o interesse pela experimentação que permitia preparar as chamadas árvores metálicas ou "árvores de Diana" a partir de soluções de sais metálicos que atraíram a atenção de muitos curiosos das práticas laboratoriais [30]. A descrição das experiências que se faziam no âmbito desta experimentação era correntemente referida como palingénesis; hoje, é preferencialmente designada por vegetação metálica.

A curiosidade pelo fenómeno narrado tornou-se grande, mesmo entre os mais cépticos. Tornou-se grande o número de curiosos que em algumas cidades, por exemplo em Paris, pagavam para assistir a experiências anunciadas e descritas como ressurreições de rosas e túlipas. Plantas "ressuscitadas" tornaram-se objectos apetecidos para exibição em Gabinetes de curiosidades de História Natural [31].

Neste contexto, na caracterização da natureza e modo de actuação da virtude fermental constitutiva de minerais e vegetais como a concebia Newton, a palingénesis servia melhor a causa dos interesses alquimistas do que a sua caracterização confinada ao fenómeno da metalogénesis. Se voltada apenas para esta, servia, como já atrás o referimos, o objectivo alquimista da transformação dos metais vis em metais nobres, mas relegava para segundo plano o grande objectivo da regeneração contínua do homem pelo uso do Elixir da longa vida, até à possibilidade de o transformar no próprio Deus.

O estudo virtude fermental pela via da metalogénesis, a vegetação metálica, assente no estudo da química mineral era mais sedutor e, porventura, mais realista, na prossecução do objectivo alquimista da transformação dos metais vis em metais nobres. Porém, o seu estudo pela via da palingénesis, assente na química vegetal, seria não só muito mais abrangente, como também mais nobre e adequado ao homem com o olhar posto no próprio Deus e comprometido na Sua Glória. E esta era uma atitude que os filósofos da Renascença não descuravam de modo algum. Newton professou-a e nela se comprometeu.

Comum a vegetais e minerais, a virtude fermental admitida por Newton como parte constitutiva de uns e outros e de que aqui nos servimos para diferenciar entre a sua concepção da química vegetal e a química dos vegetais (a fitoquímica), a química a que nos referimos hoje quando usamos a mesma terminologia, não deve ser identificada com a "força vital" do vitalismo, pois esta seria uma força de que só os seres vivos seriam dotados. Devido a ela, os seus defensores acreditavam que nenhuma substância orgânica poderia ser preparada ou produzida fora da acção de um qualquer ser vivo. Para Newton esta não era a questão. A virtude fermental de Newton, nota essencial da sua química vegetal, era a sua crença e a sua afirmação do espírito seminal de todas as coisas da filosofia química de J.B. van-Helmont.

Não consta que este pioneiro da nova química iniciada com Paracelso alguma vez se tenha interessado pela palingénesis, ou tenha escrito alguma coisa sobre ela; todavia, vários dos seus discípulos, nomeadamente Kircher, nas suas referências ao fenómeno por mais que uma vez o fizeram dizendo que ele era uma prova das teorias seminais por ele defendidas, segundo as quais todas as coisas seriam formadas a partir de sementes próprias que não seriam simples objectos materiais, mas antes o "arquê" ou ideia do seu princípio activo [32]. Para Newton, a virtude fermental seria uma dessas sementes.

\section{REFERÊNCIA}

[1] A. M. Amorim da Costa, "Nomenclatura Química portuguesa no século XVIII “, in Werner Thielmann (ed.), O Século da Luzes, Frankfurt am Main (2006) 273-292.

[2] N. Lémery, Cours de chymie, 1675.

[3] J. Béguin, Tyrocinium Chymicum E Natura Fonte et Manuali Experientia, Renatum Ruellium, Paris, 1610.

[4] T.S.Patterson, "Jean Béguin and his Tyrocinium Chymicum”, Annals of Science 2 (1937) 243-298.

[5] N. Le Febvre, Traité de Chymie, Paris, 1660.

[6] C. Glaser, Traité de la Chimie, Paris, chez l'autheur, 1663. Nota: este trata- 
do foi traduzido para inglês e publicado em Londres em 1677 com o título The Complete Chymist, respectivamente, em 1660 e 1663.

[7] D. M. Arraes, Tratado das Virtudes dos Óleos de Enxofre, Vitríolo, Philosophorum, Alecrim, Salva e Agoa Ardente, Lisboa,1648; Ms. 193 da Biblioteca Geral da Universidade Coimbra, pp. 22-22vs.

[8] A. M. Amorim da Costa, Primórdios da Ciência Química em Portugal, Lisboa, Instituto de Cultura e Língua Portuguesa, 1984, pp.29-30.

[9] J. A. Simões de Carvalho, Memória Histórica da Faculdade de Filosofia, Coimbra, Imprensa da Universidade, 1782, p. 282.

[10] I. Newton, Philosophiae Naturalis Principia Mathematica, Apud Josephi Streater, Londres, 1687.

[11] I. Newton, Opticks or a treatise of the reflections, refractions, inflections and colours of light, Sam. Smith \& Walford, London, 1704.

[12] I. Newton, op. cit. "Opticks", p. 400

[13] Unpublished Scientific Papers of Isaac
Newton, A .R. Hall e M. B. Hall (eds.), Cambridge University Press, Londres (1962) 341.

[14] A. M. Amorim da Costa, "Newton e a Química", Química - Bol. Soc. Port. Química 27 (1987) 40-42.

[15] I. Newton, Philosophiae Naturalis..., loc. cit., Auctoris Praefatio ad Lectorem.

[16] Newton e o Cálculo Diferencial Integral in http://plato.if.usp.br/1-2003/ fmt0405d/apostila/renasc7/node12. $\mathrm{html}$

[17] M. Eliade, Forgerons et Alchimistes, Flammarion Ed. Paris, 1956, pp. 47- 48.

[18] H. Cardanus, trad 1556, pp.106-108, cit. in G. Bachelard, La Terre et les Rêveries de la Volonté, Paris, 1948, 244-245.

[19] R. Bacon, Sylva Sylvarum, III, p.153 cit. in G. Bachelard, op.cit., p.244.

[20] Aristotle, Meteorologia, IV.

[21] J. A. Morris, "The Mineral Exhalation Theory of Metallogenesis in Pre-Modern Mineral Science", Ambix 53 (2006) 43-65.

[22] G. P. Secundus, Naturalis Historia, XX-XIV, 49.

[23] S. d'Amasée, Géographie, V , 2.
[24] J. Du Chesne, In Hermeticis disciplinis defensio contra Anonymum p.231; Idem, Le Grand Miroir du Monde, Lyon, 1593, p.89.

[25] J. Marx, "Alchimie et palingénésie", Isis 62 (1971) 275-289.

[26] A.G.Debus, "A Further note on Palingenesis", Isis 64 (1973) 226.

[27] F. Secret, "Palingenesis, Alchemy and metempsychosis in Renaissance medicine", Ambix 26 (1979) 81-92.

[28] C. Bonnet, Palingénése philosophique ou idées sur l'état passé et futur dês êtres vivants, 1770 .

[29] P. S. B. Lion, Essais de palingenésie social , 1833.

[30] G. Schott, Technica Curiosa Sive Mirabilia Artis, Wurzburg, 1664, 1351-1360.

[31] G. Voigt, Curiositates Physicae, de ressurrectione plantarum, cantatione cygnea, congressu et partu viperaru, chamaeleonis vitu, Gustrovi, 1668.

[32] A. M. Amorim da Costa, "No Mundo dos Fluidos: o Gás, o Blás e o Magnal de J.B. van-Helmont" in A Palavra Perdida, Lisboa, 2005, Ed. Apenas Livros, 11-26.

\section{Actualidade Científica}

\section{Uma Fusão Catalítica}

Através da combinação de duas formas de activação de moléculas bem conhecidas, a catálise fotoredox e a organocatálise, químicos da Universidade de Princeton conseguiram obter a primeira $\alpha$-alquilação de aldeídos enantioselectiva (Science, DOI: 10.1126/science.1161976).

Graças a um novo conceito de catálise combinada, esta reacção outrora complicada torna-se "trivial" do ponto de vista operacional de acordo com os investigadores responsáveis, os químicos David W. C. MacMillan e David A. Nicewicz. Para além disso, segundo estes, esta estratégia pode conduzir a avanços na investigação de outras reacções enantioselectivas.

MacMillan e Nicewicz escolheram um complexo ruténio(II) bipiridina, $\mathrm{Ru}(\mathrm{bpy})_{3}{ }^{2+}$, como catalisador fotoredox. Apesar deste agente ser já usado em algumas aplicações, tais como o armazenamento de energia, a sua utilização em síntese orgânica não é comum. Os investigadores pensaram que o complexo poderia ser usado para captar energia a partir da luz ambiente e assim, introduzir um electrão no ciclo catalítico. MacMillan salienta que os mecanismos de electrão único são vulgares na Natureza, mas que os químicos de síntese não se interessam tipicamente por eles.

No mecanismo proposto por MacMillan e Nicewicz, o complexo de ruténio gera um radical alquilo deficiente em electrões a partir de um brometo de alquilo.

Este radical combina-se com uma enamina formada pela condensação de um aldeído com um catalisador amina quiral. Uma hidrólise subsequente produz o aldeído $\alpha$-alquilado.

Como este processo apenas necessita de radiação ambiente pouco energética para activar o ciclo catalítico, e não de luz ultravioleta de alta energia, MacMillan supõe que o processo possa ser viável à escala da síntese industrial. MacMillan acredita que "este conceito pode levar a um novo paradigma para a catálise assimétrica e que ao mesmo tempo abre a porta a muitas reacções actualmente desconhecidas".

Para esse propósito, o seu grupo já aplicou o novo conceito de organocatálise fotoredox a outros tipos de transformações como trifluorometilações, aminações, benzilações e alquilocianações de aldeídos. (adaptado do artigo "A Catalytic Merger" de Bethany Halford publicado em 8/09/2008 no site Chemical \& Engineering News: http:// pubs.acs.org/cen/news/news.html).

Paulo Brito 


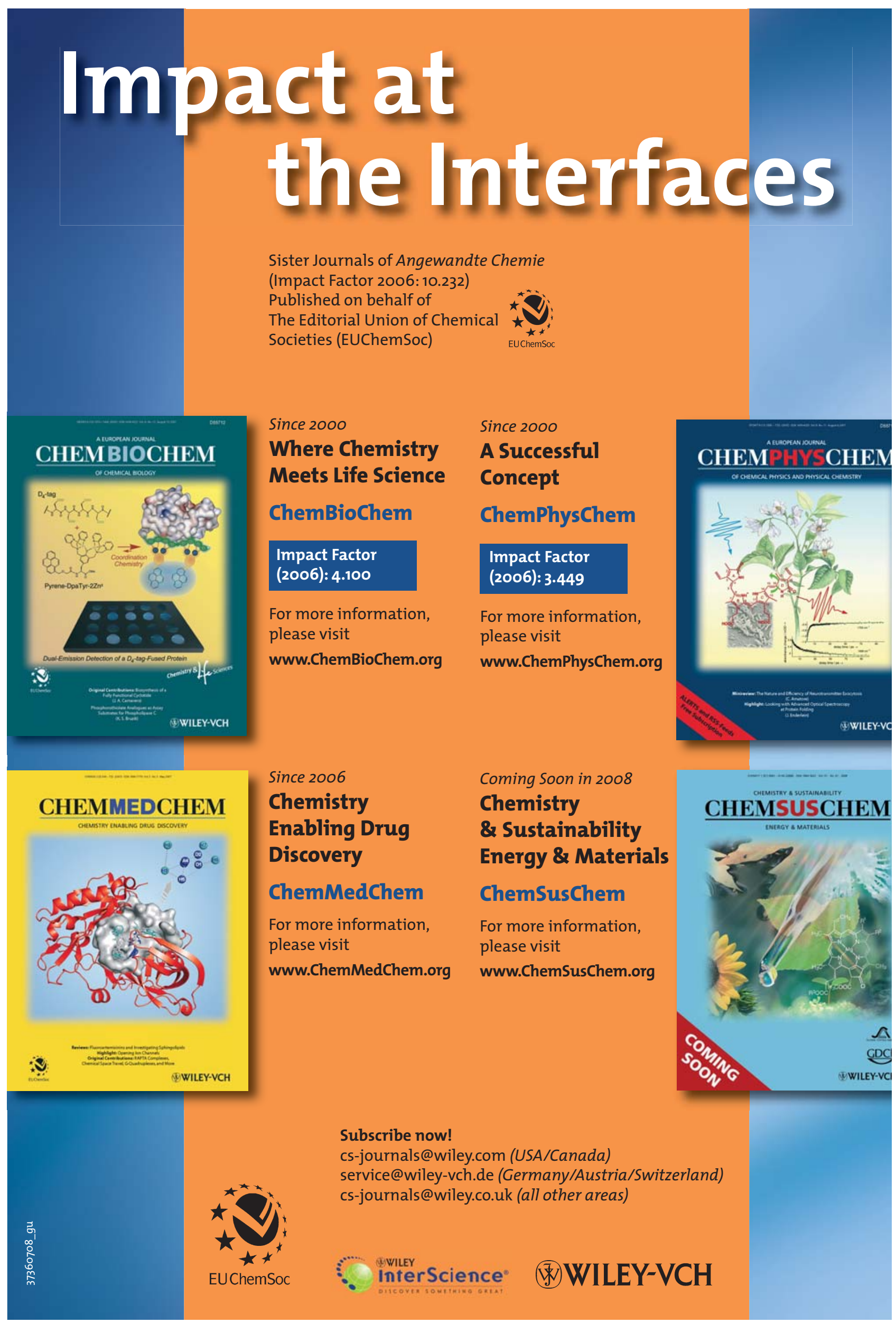




\section{Where Chemistry Meets Life Science}

14 national

chemical societies of EUChemSoc

*

are co-owners of

ChemBioChem

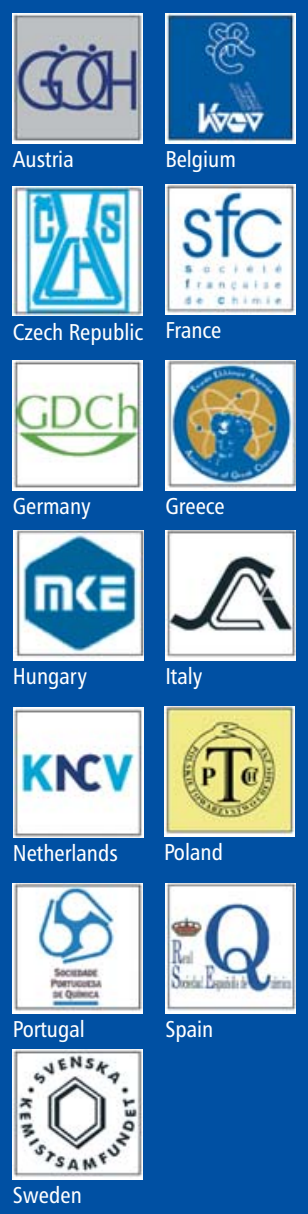

\section{Subscribe now!}

For further information and to subscribe please send an E-mail to:

cs-journals@wiley.com (North and South America)

service@wiley-vch.de (Germany/Austria/Switzerland) cs-journals@wiley.co.uk (all other areas)

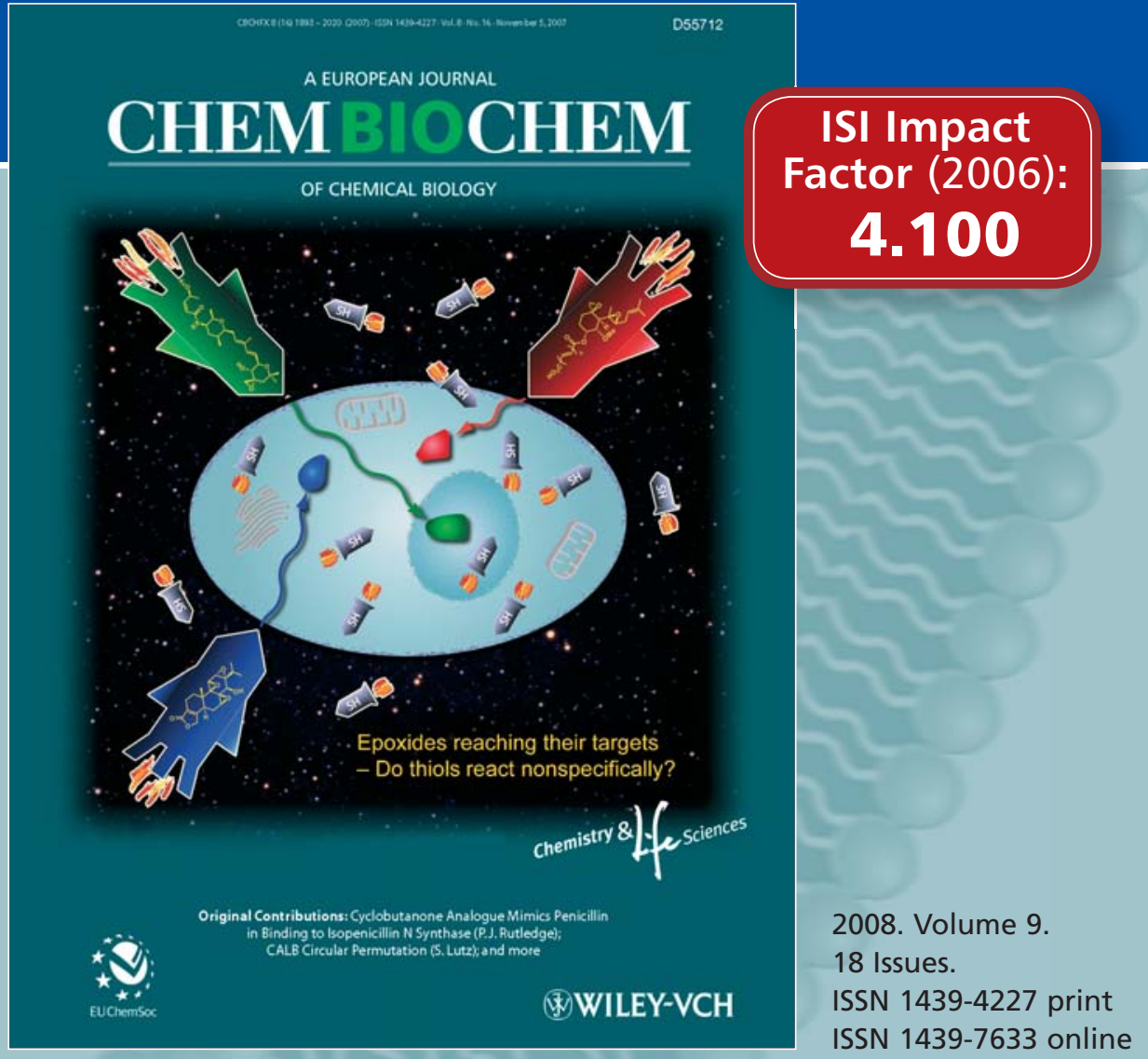

\section{ChemBioChem is}

a leading journal for chemical biology and biological chemistry covering

bioinorganic and bioorganic chemistry

biochemistry and biophysics

- molecular and structural biology

- biotechnology
Chairmen of the Editorial Advisory Board: Alan R. Fersht (UK) Jean-Marie Lehn (France)

Editor: Peter Gölitz

Deputy Editor: Lobat Doostdar Managing Editor: Lisa Abel

\section{ChemBioChem offers:}

FREE Table of Contents

Early View - fully citable articles ahead of the printed version

- $\mathrm{RSS}$ feeds: Be automatically informed of new articles as soon as they are published online

- An attractive mixture of Communications, Full Papers, Reviews \& Minireviews

\section{Visit ChemBioChem online www.chembiochem.org}

